\title{
Preventing bullying through science, policy, and practice [La prevención del bullying a través de la ciencia, la política y la práctica].
}

\begin{abstract}
Rivara, F. y Le Menestrel, S. (Eds.). Preventing bullying through science, policy, and practice [La prevención del bullying a través de la ciencia, la política y la práctica]. Washington, DC: The National Academies Press, 2016, 361 pp., ISBN 978-0-309-44067-7.
\end{abstract}

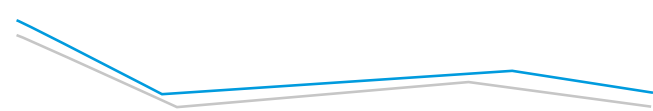

Guadalupe Ruiz Cuéllari*

Ruiz Cuéllar, G. Preventing bullying through science, policy, and practice [La prevención del bullying a través de la ciencia, la política y la práctical. Reseña. Investigación y Ciencia de la Universidad Autónoma de Aguascalientes. Número 68: 99-101, mayo-agosto 2016.

El libro Preventing bullying through science, policy, and practice [La prevención del bullying a través de la ciencia, la política y la práctica] es una obra recientemente publicada (2016) por la National Academy Press. Reconociendo que el bullying (acoso escolar) es un problema de salud pública que exige acciones concertadas y atención de los padres, educadores y administradores de escuelas, profesionales de la salud, elaboradores de políticas, familias, y otras instancias relacionadas con el cuidado de los niños y jóvenes, un grupo de agencias federales y fundaciones privadas encomendó a las Academias Nacionales de Ciencias, Ingeniería y Medicina de Estados Unidos llevar a cabo un estudio de lo que se conoce y lo que se necesita saber para reducir el bullying y sus consecuencias.

El Committee on the Biological and Psychosocial Effects of Peer Victimization: Lessons for Bullying Prevention fue creado para llevar a cabo esta tarea. El Comité integró expertos en múltiples campos y asumió una definición del bullying que comprende los elementos usualmente contemplados en el abordaje de esta problemática: i) conducta agresiva no deseada por quien es objeto de ella; ii) que implica un desequilibrio observado o percibido de poder; iii) que se repite varias veces o es altamente probable que se repita; iv) que inflige daño o angustia en los niños y jóvenes que son objeto de ella, incluyendo daño físico, psicológico, social o educativo.

Además de la Introducción, la obra está integrada por seis capítulos. En el primero, "El alcance del

Departamento de Educación, Centro de Ciencias Sociales y

Humanidades, Universidad Autónoma de Aguascalientes.

* Autor para correspondencia: gruiz@correo.vaa.mx

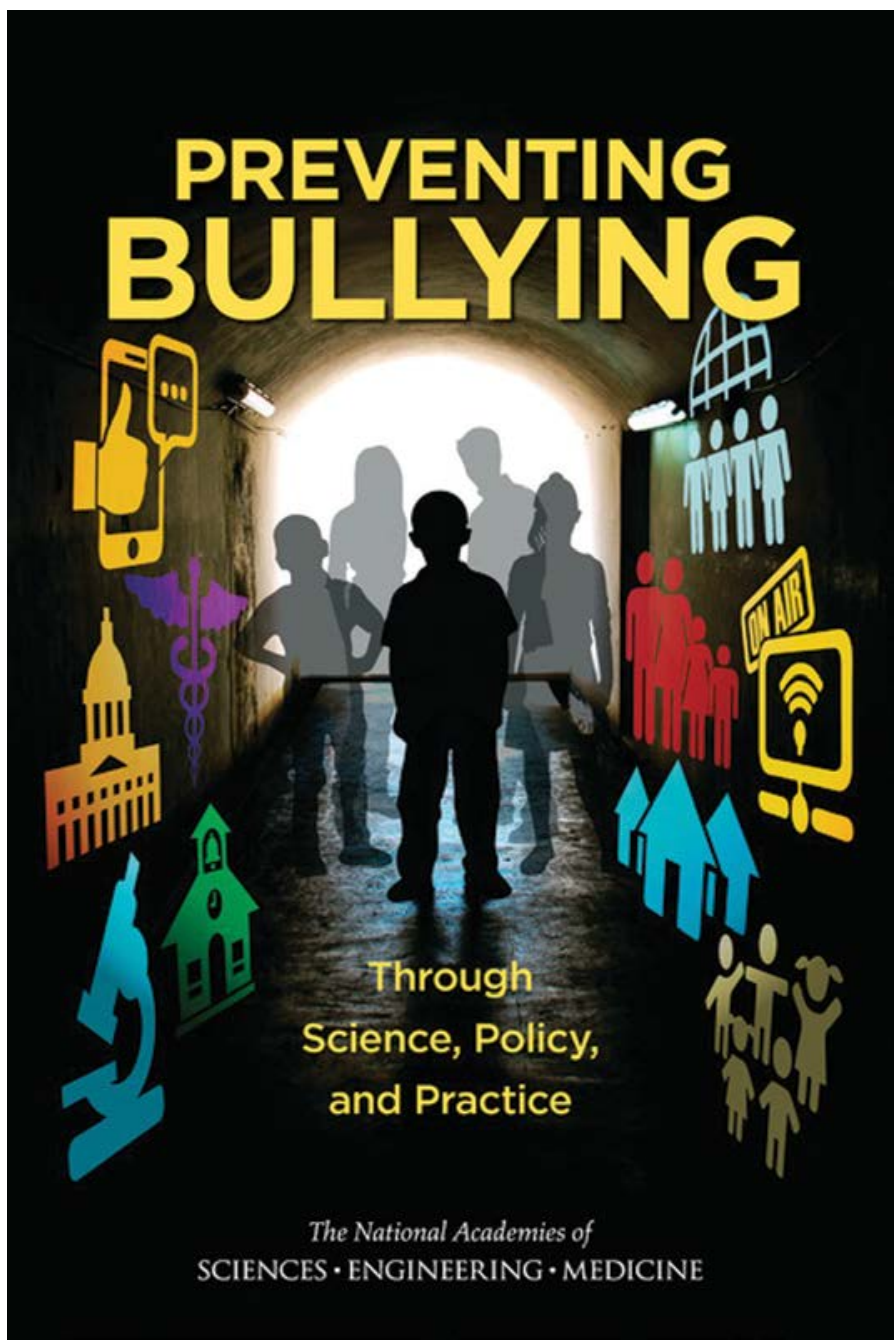

Portada del libro Preventing bullying through science, policy, and practice [La prevención del bullying a través de la ciencia, la política y la práctica]. 
problema", se presentan datos sobre el bullying en Estados Unidos y se señalan factores que hacen difícil generar una estimación precisa, consistente y representativa de las tasas de bullying y cyberbullying, lo que no obsta para saber que se trata de un problema real que afecta a una gran cantidad de niños y jóvenes. Entre los contenidos relevantes de este capítulo figuran los siguientes:

- Las bases de datos nacionales acerca de la prevalencia del bullying se focalizan principalmente en los niños que son acosados. Considerablemente menor es el conocimiento acerca de los perpetradores o acosadores y no hay conocimiento acerca de los testigos. Además, se carece de datos representativos para ciertos grupos que están en riesgo de sufrir bullying, tales como los jóvenes de minorías sexuales o aquellos con discapacidades, entre otros.

- Diferentes tipos de bullying -físico, relacional, cibernético- pueden surgir o ser más relevantes en diferentes etapas de vida de las personas.

El siguiente capítulo, "Los individuos dentro de los contextos sociales", plantea ideas importantes como las siguientes:

- Los niños y jóvenes están inmersos en múltiples contextos, que van desde los compañeros y la familia hasta la escuela, la comunidad y el macrosistema. Cada uno de estos contextos puede afectar a niños y jóvenes en formas que exacerban o atenúan la asociación entre características individuales como la etnia, orientación sexual o alguna condición de discapacidad, y la perpetración y/o el ser objeto de conductas de bullying.

- Los factores contextuales operan de manera distinta entre grupos de jóvenes y, por tanto, los contextos que protegen a algunos de ellos de los efectos negativos del bullying no son generalizables a todos los jóvenes.

- El estudio de experiencias de bullying en subgrupos particularmente vulnerables no puede ser separado de los estudios de discriminación o de trato injusto con base en estigmatizaciones. En este sentido, debería haber mucha más interacción entre los estudios empíricos del bullying escolar y la discriminación debida a estigmas sociales.
El capítulo sobre las consecuencias de las conductas de bullying plantea que estas no se reducen al corto plazo sino que suelen ser de más largo alcance y no solo afectan a los niños y jóvenes que son acosados, sino también a los acosadores y a los testigos. El rango incluye consecuencias sobre la salud física pero también sobre la psicológica, estrés, depresión, tendencias suicidas, problemas de autorregulación, cognitivos y de desempeño escolar, proclividad a otros tipos de violencia y delincuencia, entre otros.

El quinto capítulo está dedicado a las "Intervenciones preventivas", y la manera en que pueden mejorar su calidad y eficacia. Entre las principales conclusiones destacan las siguientes:

- Los programas escolares selectivos parecen ser más eficaces para reducir el bullying que los de alcance universal; a través de estos, todos los miembros de la población objetivo están expuestos a la intervención sin tener en cuenta el riesgo específico de acoso escolar que enfrentan. Las intervenciones preventivas selectivas están dirigidas ya sea a los jóvenes que están en riesgo de acosar o a los jóvenes en riesgo de ser blanco del bullying.

- Las familias juegan un rol crucial en la prevención del bullying al igual que los testigos; de ahí que su involucramiento en intervenciones preventivas sea recomendable.

- Las escuelas pueden considerar la implementación de programas multicompo-nentes, centrados en el clima escolar, el apoyo al comportamiento positivo, el aprendizaje social y emocional, o la prevención de la violencia de manera más general.

El capítulo sobre "Leyes y políticas" remarca que:

- El desarrollo de políticas y leyes antibullying debe basarse en evidencias. Se necesita investigación adicional para determinar los componentes específicos de una ley contra el bullying que sea más eficaz en la reducción de este fenómeno.

- Algunas políticas y programas han demostrado ser ineficaces en la prevención del bullying; es el caso de las políticas de tolerancia cero. 
El último capítulo formula recomendaciones para diferentes agencias e instancias de gobierno federales y estatales de los Estados Unidos. Con variaciones propias de cada contexto, son medidas valiosas para otros países; cabe mencionar: el uso de una definición coherente del bullying que favorezca la identificación consistente de su prevalencia; la recolección de datos longitudinales, no solo transversales, sobre la prevalencia de todas las formas de bullying (física, verbal, cibernética); la evaluación del papel del estigma y los prejuicios en la conducta del bullying; y la formación en prevención del bullying de las personas que trabajan directamente con niños y adolescentes.

El estudio del bullying es un campo relativamente reciente. Durante las últimas décadas la investigación ha mejorado significativamente la comprensión de esta problemática, la forma en que se puede medir y los factores contextuales críticos involucrados. Si bien no hay una solución rápida o única, la evidencia apoya claramente las políticas y prácticas preventivas y de intervención, lo que puede hacer una diferencia significativa en las vidas de muchos niños y jóvenes. 